\title{
RESPONSES OF THE ISOLATED SYMPATHETIC NERVE- DUCTUS DEFERENS PREPARATION OF THE GUINEA-PIG
}

\author{
BY \\ S. HUKOVIĆ \\ From the Department of Pharmacology, Medical Faculty, University of Sarajevo, \\ Yugoslavia
}

(RECEIVED JANUARY 9, 1961)

\begin{abstract}
An isolated ductus deferens preparation together with the sympathetic hypogastric nerve of the guinea-pig is described. While the preparation showed no spontaneous contractions, nerve stimulation produced longitudinal contractions. The responses to successive periods of nerve stimulation remained constant for several hours. After noradrenaline had been added to the bath fluid for $30 \mathrm{~min}$ and then the fluid repeatedly changed to wash out the noradrenaline, the effect of nerve stimulation was greatly increased but declined in the course of $1 \mathrm{hr}$ to the original height. Cocaine also increased the response to stimulation. Preparations made from guinea-pigs which had previously received reserpine responded to nerve stimulation with progressively diminishing contractions. In these circumstances, the administration of noradrenaline restored the response to nerve stimulation to that seen originally.
\end{abstract}

This paper describes the effect of noradrenaline and cocaine on the response to electrical stimulation of the nerve to the isolated ductus deferens preparation of the guinea-pig.

\section{METHODS}

Guinea-pigs were killed by a blow on the head and bled out. The animal was fixed on its back on the operating table, the abdomen opened in the mid-line and the gut displaced to the right. The testes were pushed into the abdominal cavity by pressure on the scrotum. Holding one testis, the ductus deferens was freed from connective tissue and cut from the epididymis. The testis was then removed. Grasping the cut end of the ductus deferens with small forceps, it was separated from the adjacent tissue. Without further cleaning of the ductus deferens, the hypogastric nerves were identified. The right and left nerves can easily be seen in the middle of the mesentery of the colon. One nerve was tied, and cut $5 \mathrm{~cm}$ from the ductus deferens; this was cleaned to within $0.5 \mathrm{~cm}$ of the organ. The remainder of the nerve up to the ductus deferens, which is fine and diffuse, was preserved by isolating the piece of peritoneum which contained it. The ductus deferens was then cut from the urethra and removed together with its nerve and the small piece of peritoneum to a bath of Krebs solution. During the dissection the organ and nerve were moistened with Krebs solution. A second satisfactory preparation can be made from the contralateral side, for speed in preparation is not essential.

The ductus deferens was tied by its proximal end to a hollow glass rod and set up in an isolated organ bath containing $12 \mathrm{ml}$. of Krebs solution at $31^{\circ} \mathrm{C}$ bubbled with $5 \%$ carbon dioxide and $95 \%$ oxygen. The distal end of the ductus was attached to a lever which wrote on a smoked paper. The hypogastric nerve was passed through the channel of a pair of electrodes of the pattern described by Burn \& Rand (1960a) situated below the meniscus of the bath fluid. A vibrator attached to the frame of the organ bath improved recordings. The preparation was stimulated submaximally by rectangular pulses of 2 to $3 \mathrm{~V}$ and of $2 \mathrm{msec}$ 
duration at a frequency of $80 / \mathrm{sec}$. The preparation was stimulated for 2 to $3 \mathrm{sec}$ every min. Similar preparations can be made from rabbits, rats and mice.

The composition of the Krebs solution used was: $\mathrm{NaCl} 6.60 \mathrm{~g}, \mathrm{KCl} 0.35 \mathrm{~g}, \mathrm{CaCl}_{2} 0.28 \mathrm{~g}$, $\mathrm{KH}_{2} \mathrm{PO}_{4} 0.162 \mathrm{~g}, \mathrm{MgSO}_{4} 7 \mathrm{H}_{2} \mathrm{O} 0.294 \mathrm{~g}$, dextrose $2.08 \mathrm{~g}, \mathrm{NaHCO}_{3} 2.10 \mathrm{~g}$, in 1 l. of distilled water.

\section{RESULTS}

When set up in Krebs solution, the preparation from the guinea-pig exhibited no spontaneous contractions. Contractions of the ductus deferens with repetitive electrical stimulation of the hypogastric nerve were quick and strong, and are

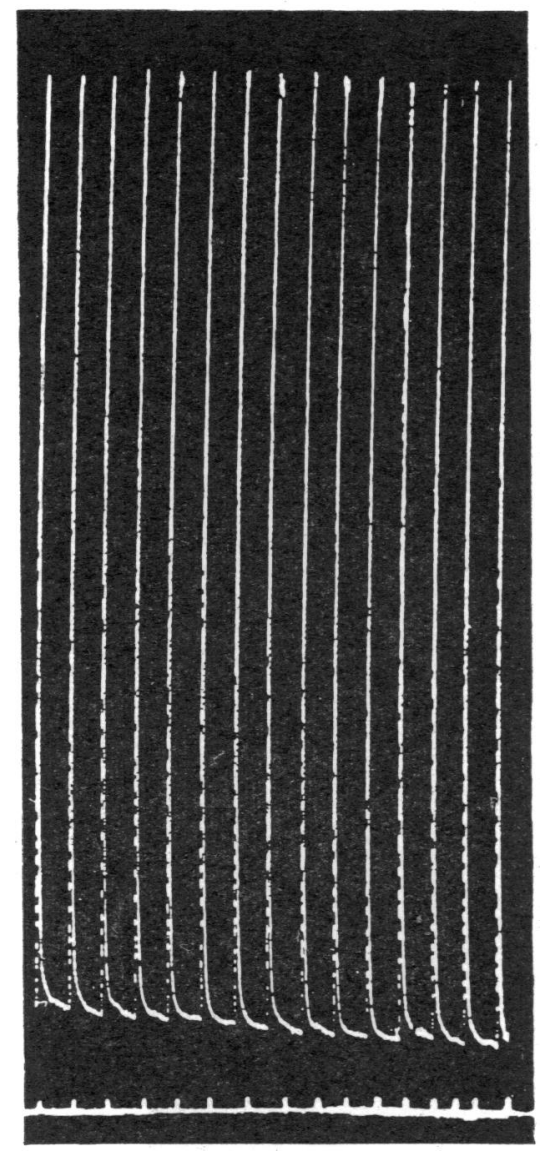

Fig. 1

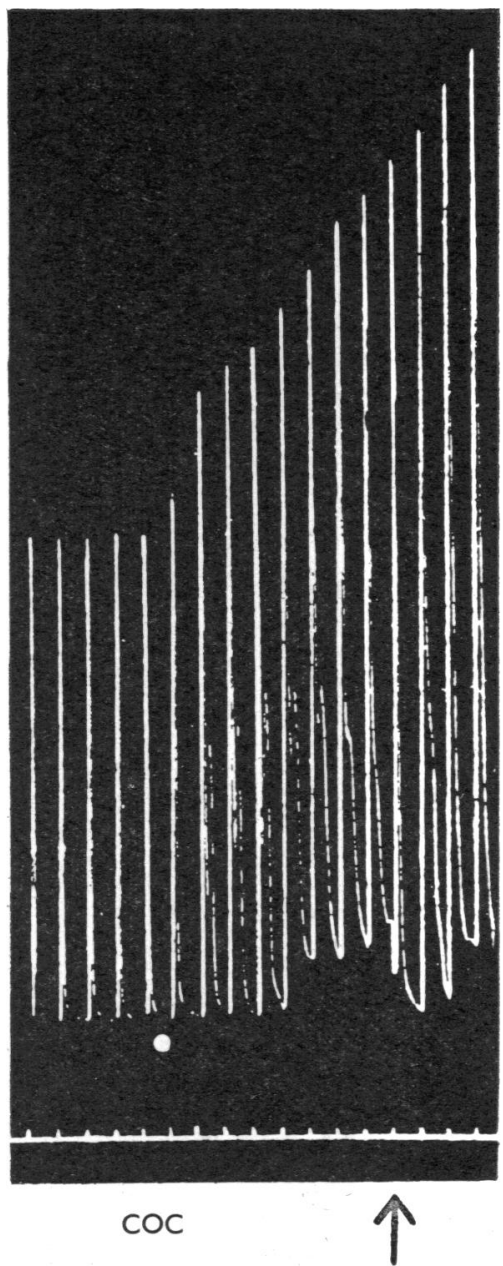

Fio. 2

Fig. 1. Record of the contractions of the isolated ductus deferens preparation of the guinea-pig in response to submaximal stimulation $(2 \mathrm{~V}, 2 \mathrm{msec}, 80$ pulses'sec) of the hypogastric nerve for $2 \mathrm{sec}$ in each min. Time, min.

Fig. 2. Records as in Fig. 1. At the white dot (COC) cocaine was added to the bath in a concentration of $15 \times 10^{-6} \mathrm{~g} / \mathrm{ml}$. At the arrow the bath was washed out. Time, min. 
shown in Fig. 1. There was very little decrease in the height of the responses when contractions were produced at intervals of $1 \mathrm{~min}$ for several hours. The responses of preparations isolated from rabbits, rats and mice were similar.

Cocaine. The effect of cocaine $\left(15 \times 10^{-6} \mathrm{~g} / \mathrm{ml}\right.$.) on the response to nerve stimulation was observed on 12 preparations each from different guinea-pigs. In 5 experiments the response to stimulation was greatly increased. Fig. 2 shows that the effect of cocaine developed gradually and continued after washing, at the arrow.

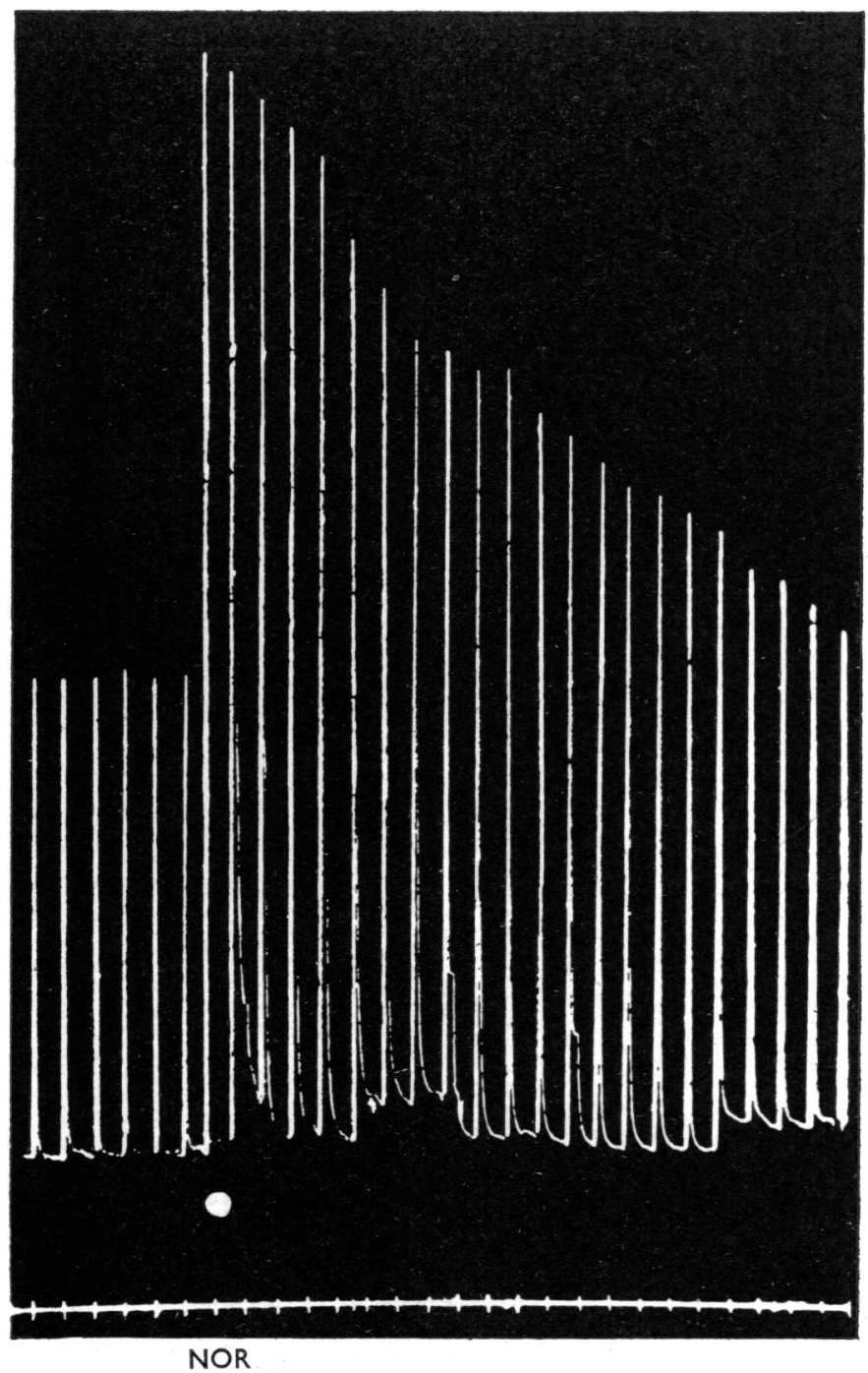

Fig. 3. Record as in Fig. 1. At the white dot (NOR) the kymograph was stopped, stimulation suspended and noradrenaline $(15 \mu \mathrm{g} / \mathrm{ml}$.) was added. After $30 \mathrm{~min}$, the bath was washed out 5 times at 3-min intervals, the kymograph was then re-started and stimulation resumed. Time, $\min$. 
In 4 experiments the increase was small and in 3 there was a decrease. However, in these 7 experiments, the contractions after washing out the cocaine were greater than before its administration.

Noradrenaline. Noradrenaline $(15 \mu \mathrm{g} / \mathrm{ml}$.) left in contact with the guinea-pig ductus deferens preparation for $30 \mathrm{~min}$ caused a contraction. On washing every $3 \mathrm{~min}$ for $15 \mathrm{~min}$, the ductus relaxed nearly to the original base line. The height of the response to nerve stimulation after treatment with noradrenaline was always found to be at least twice as great as that seen before the application of noradrenaline (Fig. 3).

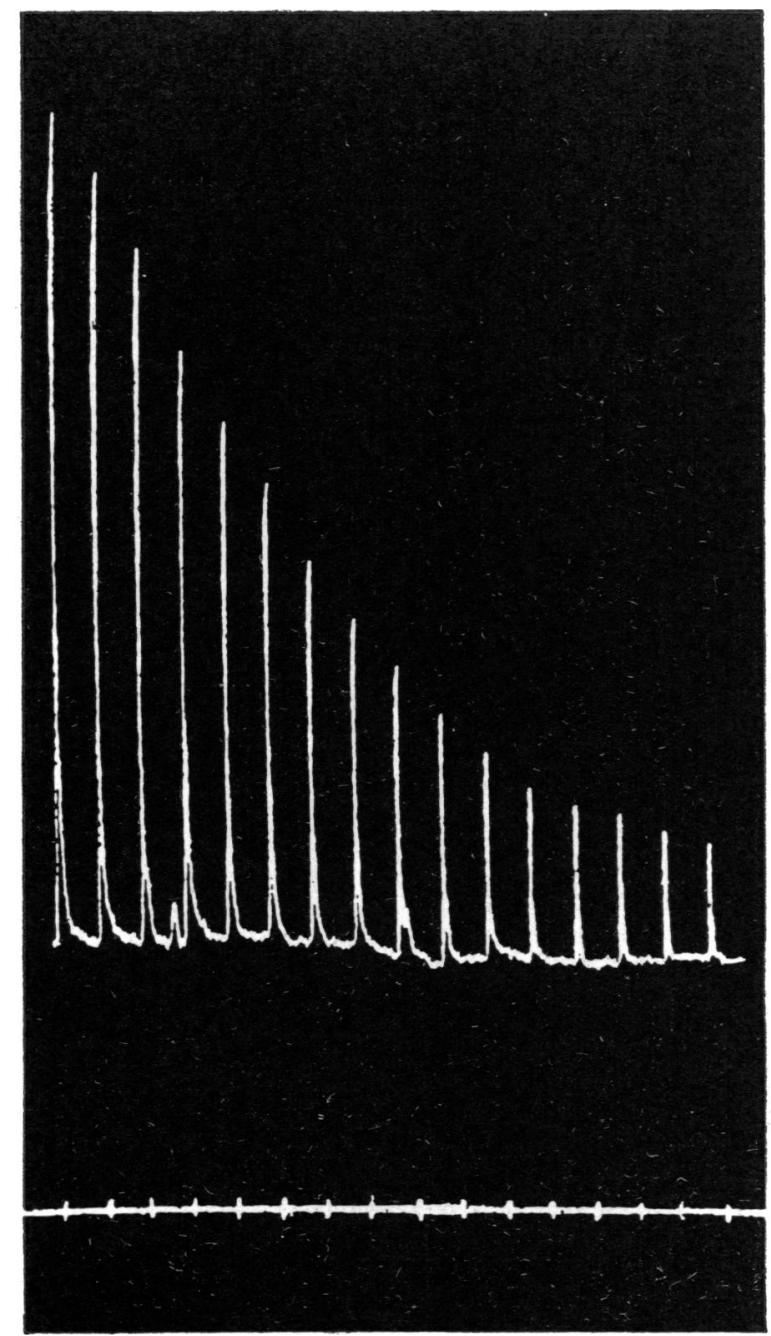

Fig. 4. Record as in Fig. 1. The ductus deferens preparation was made from a guinea-pig treated for 2 days previously with reserpine (see text). Note the progressive decrease in response to stimulation. Time, min. 
Reserpine. Preparations of the ductus deferens were made from guinea-pigs which had received intraperitoneally for the 2 days previously $0.5 \mathrm{mg} / \mathrm{kg}$ of reserpine on the first day and $1.0 \mathrm{mg} / \mathrm{kg}$ on the second day. In all these preparations a progressive decrease in the response to stimulation was seen after the first 2 or 3 periods of stimulation, but the contractions were never completely abolished (Fig. 4).

Effect of noradrenaline after reserpine. Fig. 5a shows small and regular contractions in response to nerve stimulation of a ductus from a reserpine-treated guinea-pig. Noradrenaline $(15 \mu \mathrm{g} / \mathrm{ml}$.) added to the bath caused a marked contraction. The noradrenaline was left in the bath for $30 \mathrm{~min}$. After washing every $3 \mathrm{~min}$ for 15 min, the ductus relaxed nearly to the base line. The response to nerve stimulation was then seen to be increased to more than 4 times its initial height (Fig. 5b). The

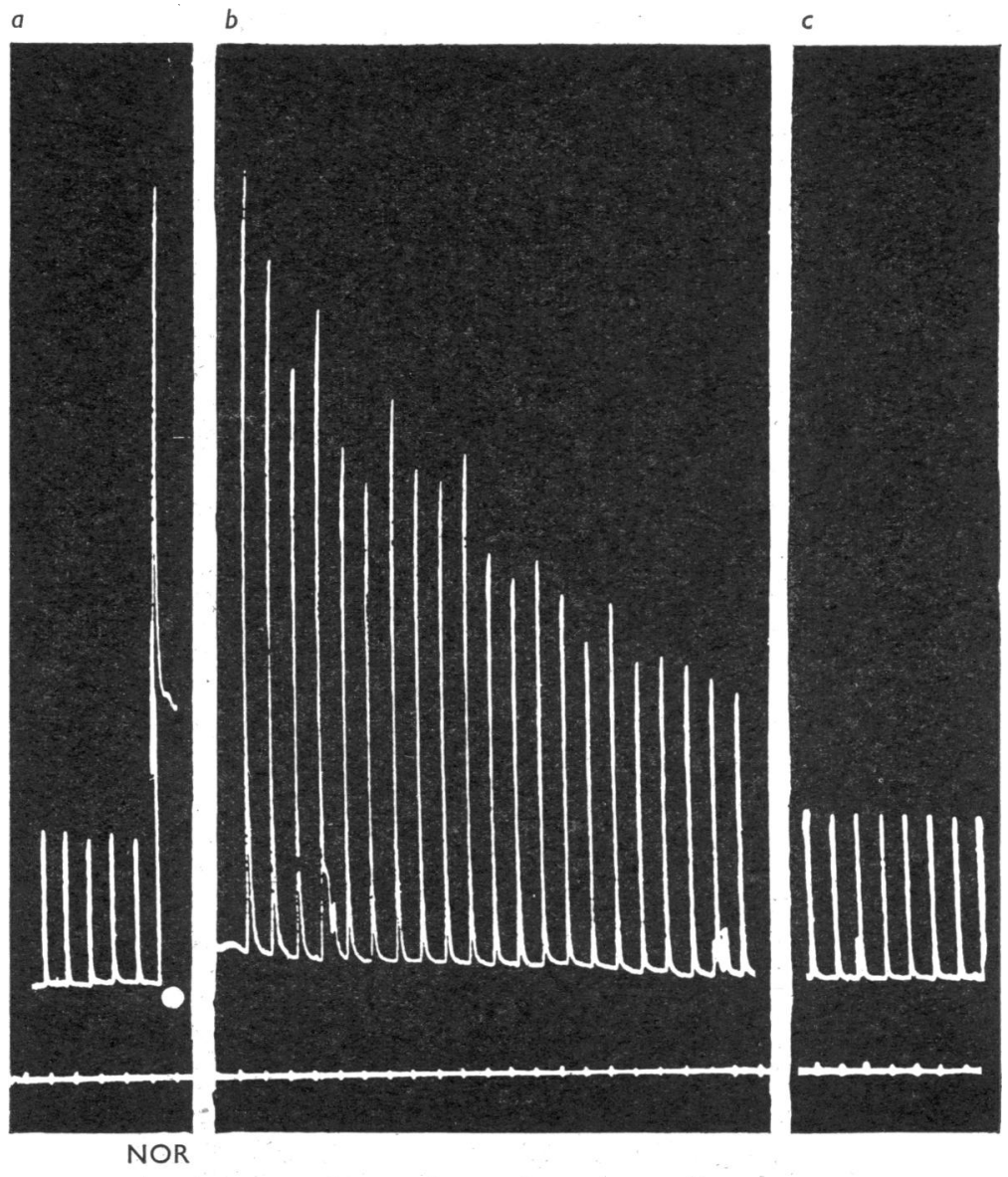

Fig. 5. Records as in Fig. 1 from a ductus deferens preparation of a guinea-pig previously treated with reserpine (see text). (a) At the white dot (NOR) noradrenaline (15 $\mu \mathrm{g} / \mathrm{ml}$.) was added and then washed out as in Fig. 3. (b) When stimulation was resumed the contractions were at first enhanced, but in (c) 60 min later they had declined to their initial heights. 
potentiated responses to stimulation gradually decreased, until $1 \mathrm{hr}$ later they were no larger than those before noradrenaline (Fig. 5c).

The potentiation of the responses to stimulation of the nerve by noradrenaline both in the normal and in the reserpine-treated preparation was much greater than that seen after resting the preparation for $45 \mathrm{~min}$.

\section{DISCUSSION}

Stimulation of the hypogastric nerve of rabbits causes contractions of the uterine cornu and cervix in situ (Schofield, 1952) and of the cornu in vitro (Varagic, 1956). Mann \& West (1951) recovered adrenaline and noradrenaline from blood in the ovarian vein after stimulation of hypogastric nerves to the uterus of the cat. In most species the sympathetic outflow to the uterus is motor and the chief route is through the hypogastric nerves (Garry, 1957). These same sympathetic hypogastric nerves in the male supply motor innervation to the ductus deferens. The preparation of the isolated ductus deferens with its hypogastric nerve described here is easy to make, durable, and gives uniform contractions to nerve stimulation.

Schofield (1952) found that cocaine did not increase the contraction of the rabbit uterus in response to stimulation of the hypogastric nerve in situ. However, in the in vitro preparation of the rabbit uterus, Varagic (1956) found an increased response. In nearly half of the present experiments with the guinea-pig ductus deferenshypogastric nerve preparation, cocaine potentiated responses; but in some experiments it caused inhibition. However, after washing out cocaine from the bath the potentiating effect due to cocaine was then seen. It is possible that inhibition, when it occurred, was due to the local anaesthetic effect of cocaine on the hypogastric nerve.

Stores of noradrenaline have been detected in a number of tissues, such as the heart (Bertler, Carlsson \& Rosengren, 1956), arteries (Burn \& Rand, 1958), iris and spleen (Burn \& Rand, 1959) and skin of the cat's tail (Burn, Leach, Rand \& Thompson, 1959). These stores of noradrenaline can be depleted by treatment with reserpine and then the usual responses to sympathetic stimulation are reduced or abolished (Muscholl \& Vogt, 1958; Burn, Leach, Rand \& Thompson, 1959; Hukovic, 1959). The results with ductus preparations from reserpine-treated guineapigs are compatible with a similar depletion of the noradrenaline stores of the ductus, so that stimulation of the nerve could only release small amounts of noradrenaline from the reduced store.

After treating the ductus preparation with noradrenaline, the responses to hypogastric nerve stimulation were enhanced. This observation is in accord with the findings of others that noradrenaline enhanced or restored the responses to sympathetic nerve stimulation (Gillespie \& Mackenna, 1959; Burn \& Rand, 1960a and $b$ ). The effect of noradrenaline potentiating responses to sympathetic stimulation may be due to a reloading of the depleted stores ; this suggestion is supported by the observation of Pennefather \& Rand (1960) that an infusion of noradrenaline increased the noradrenaline content of the uterus and kidney of the cat.

This work was started in the Department of Pharmacology, University of Oxford, during the tenure of a British Council Fellowship. I am indebted to Professor J. H. Burn for his help and advice and to Dr. M. J. Rand for assistance with the preparation of the manuscript. 


\section{REFERENCES}

Bertler, Å., Carlsson, A. \& Rosengren, E. (1956). Release by reserpine of catechol amines from rabbits' hearts. Naturwissenschaften, 43, 521 .

BURN, J. H. \& RAND, M. J. (1958). Noradrenaline in artery walls and its dispersal by reserpine. Brit. med. J., 1, 903-908.

BURN, J. H. \& RAND, M. J. (1959). The cause of the supersensitivity of smooth muscle to noradrenaline after sympathetic degeneration. J. Physiol. (Lond.), 147, 135-143.

BURN, J. H. \& RAND, M. J. (1960a). The relation of circulating noradrenaline to the effect of sympathetic stimulation. J. Physiol. (Lond.), 150, 295-305.

BURN, J. H. \& RAND, M. J. (1960b). The effect of precursors of noradrenaline on the response to tyramine and sympathetic stimulation. Brit. J. Pharmacol., 15, 47-55.

BuRn, J. H., LeACH, E. H., RAND, M. J. \& ThOMPSON, J. W. (1959). Peripheral effects of nicotine and acetylcholine resembling those of sympathetic stimulation. J. Physiol. (Lond.), 148, 332352.

GARRY, R. C. (1957). Innervation of abdominal viscera. Brit. med. Bull., 13, 202-206.

Gillespie, J. S. \& MACKENNA, B. R. (1959). The effect of reserpine on the response of the rabbit ileum and colon to stimulation of their extrinsic nerves in vitro. J. Physiol. (Lond.), 147, 31-32P.

Huković, S. (1959). Isolated rabbit atria with sympathetic nerve supply. Brit. J. Pharmacol., 14, 372-376.

MANN, M. \& WEST, G. B. (1951). The nature of uterine and intestinal sympathin. Brit. J. Pharmacol., 6, 79-82.

Muscholl, E. \& VoGT, M. (1958). The action of reserpine on the peripheral sympathetic system. J. Physiol. (Lond.), 141, 132-155.

Pennefather, J. N. \& RAND, M. J. (1960). The increase in the content of noradrenaline in tissues after the infusion of noradrenaline, dopamine and L-DOPA. J. Physiol. (Lond.), 154, 277-287.

SCHOFIELD, B. M. (1952). The innervation of the cervix and cornu uteri in the rabbit. J. Physiol. (Lond.), 117, 317-328.

VARAGIć, V. (1956). An isolated rabbit hypogastric-nerve-uterus preparation, with observations on the hypogastric transmitter. J. Physiol. (Lond.), 132, 92-99. 